\title{
Synthesis and properties of ion-exchange materials based on hydrolysis lignins
}

\author{
Olga Popova $^{*}$, and Tatyana Finochenko ${ }^{2}$ \\ ${ }^{1}$ Don State Technical University, Gagarin sq., 1, Rostov on Don, 344003, Russia \\ ${ }^{2}$ Rostov State Transport University, Rostovskogo Strelkovogo Polka Narodnogo Opolcheniya Sq., 2, \\ Rostov-on-Don, 344038, Russia
}

\begin{abstract}
Hydrolytic lignin is a large-tonnage waste product of ethyl alcohol production and is a renewable resource. The structure of lignin is characterized by the presence of a large number of hydroxyl groups, which provides the value of lignin as a raw material for synthesis in polymer chemistry. But due to their low chemical stability in dilute alkalis, acids and solvents, lignins are of little use for wide practical use. The introduction of additional functional groups into the lignin maromolecule by oxidative modification with the use of resource-saving technologies makes it possible to obtain new products for the synthesis of composite materials. On the basis of electrochemically modified lignin in polycondensation reactions with phthalic acid, ion-exchange materials have been obtained: weakly acidic cation exchangers with a exchange capacity of $0.1 \mathrm{~mol} / 1 \mathrm{NaOH} 3.5-3.8 \mathrm{mmol} / \mathrm{cm}^{3}$, capable of sorbing cations in a wide range of $\mathrm{pH}$ values, and ampholyte (exchange capacity for sodium cation $6.4-6.6 \mathrm{mmol} / \mathrm{cm}^{3}$, for chlorine anion - 1.1-1.3 $\mathrm{mmol} / \mathrm{cm}^{3}$ ). Ion exchangers synthesized on the basis of chlorine and nitro-containing lignins have been investigated in comparison with generally known industrial ion exchangers; they have high exchange and physic-mechanical characteristics and chemical resistance.
\end{abstract}

\section{Introduction}

The development of biologically based composites and nanocomposites is extremely important in the current environmental situation [1]. Lignins contain many hydroxyl groups that can participate in chemical reactions to produce value-added products [2]. The ability of natural lignins to adsorb organic and inorganic substances is due to the developed surface structure and interaction of functional groups, as well as the presence of hydrogen bonds.

The GL structure is formed in the process of percolation hydrolysis, which is carried out at elevated pressures (0.6-0.9 MPa) and temperatures up to $200{ }^{\circ} \mathrm{C}$. In this case, a significant modification of the lignin macromolecule occurs. As a result, in contrast to the

\footnotetext{
* Corresponding author: olvp2808@rambler.ru
} 
structure of natural lignin, the GL structure is characterized by a significantly higher content of the condensed aromatic system and a low content of functional groups (Fig. 1). A deeper thermolysis of GL leads to the production of a carbon material, and then, under appropriate thermal conditions, graphites are obtained [3-5], which have a large specific surface area and are promising for creating new nanocomposite membranes and filters with high chemical and thermal stability.

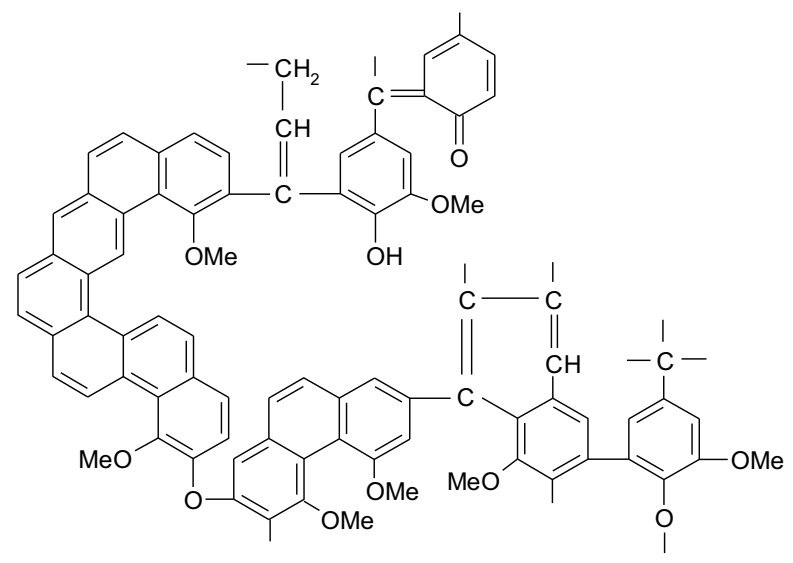

Fig. 1. The structure of a fragment of the GL macromolecule according to M. Chudakov.

Adsorbents have a wide range of industrial applications, but they are mostly expensive [1]. In the production of ion-exchange materials, it is important to use cheap sorbents, which, along with a high ion-exchange capacity, would have good physicochemical and physicomechanical characteristics.

For the use of GL as a reactive component in materials technology, it is advisable to increase its functional capacity by modification. Oxidative modification of GL by electrochemical [6-8] and other methods [9, 10] leads to an increase in the content of functional groups and, accordingly, in the sorption capacity of the lignin macromolecule. One of the effective modern approaches to the manufacture of adsorbents is the synthesis of metal / metal oxide nanocomposites on a lignin base $[11,12]$.

Due to the low chemical stability of lignins in dilute alkalis, acids, and solvents, they are of little use for widespread practical use. To increase the chemical resistance and mechanical strength of modified lignins, various methods of their processing are used: they deepen the process of polycondensation of lignins by thermal high-temperature treatment or the action of strong mineral acids at high temperatures [13] or carry out additional crosslinking of the lignin macromolecule with organic substances [14].

This publication presents the synthesis and properties of ion-exchange materials based on chlorine-, fluorine- and nitro-containing modified polyfunctional lignins and phthalic acid.

\section{Synthesis and functional composition of modified lignins}

To obtain ion-exchange materials, we first carried out the electrochemical modification of the GL of the corn cob. Lignin was previously ground in a ball mill and sieved. 
The method of sequential electrochemical modification of GL was used to obtain polyfunctional lignins (CINL - chlorine-nitro-lignin, FClL - fluorine-chlorine-lignin, ClFL - chlorine-fluorine-lignin, NCIFL - nitrated chlorine-fluorine-lignin) [8].

Chlorination of lignins was carried out in an aqueous solution of $\mathrm{NaCl}$ at elevated pressure. The use of increased pressure, on the one hand, makes it possible to increase the rate of chlorination; on the other hand, the process is carried out in sealed apparatus, which contributes to an increase in the environmental safety of production. Fluorination and nitration of lignins were also carried out in aqueous solutions under conditions of electrolyte regeneration [8]. Thus, modified lignins with different functional compositions were obtained [15] (Table 1).

Table 1. The functional composition of modified lignins.

\begin{tabular}{|c|c|c|c|c|c|c|c|}
\hline Content, \% & FL & CIL & NL & CINL & CIFL & FCIL & NCIFL \\
\hline -COOH & 26.0 & 32.5 & 16.2 & 24.0 & 22.8 & 23.0 & 24.6 \\
\hline- OH aliphatic & 0.3 & 3.1 & 19.5 & 11.5 & - & - & - \\
\hline- OH phenolic & 0.2 & 1.8 & 6.0 & 4.8 & 1.7 & 1.3 & 1.9 \\
\hline$=$ CO total & 3.4 & 18.4 & 17.1 & 12.5 & 23.0 & 21.5 & 23.0 \\
\hline$-\mathrm{Cl}$ & - & 35.0 & - & 22.3 & 19.8 & 9.2 & 12.3 \\
\hline$-\mathrm{F}$ & 5.6 & - & - & - & 2.4 & 5.2 & 4.3 \\
\hline$-\mathrm{N}$ & - & - & 3.2 & 2.8 & - & - & 2.5 \\
\hline
\end{tabular}

\section{Synthesis of ion exchange materials}

Electrochemically modified lignins containing chlorine in their structure and active functional groups - carboxyl $(-\mathrm{COOH})$, hydroxyl phenolic $(-\mathrm{OH}$ phen), and hydroxyl aliphatic ( $-\mathrm{OH}$ aliph) - were used for the synthesis of ion exchange materials. The polycondensation of lignins with phthalic acid was carried out at a temperature of 200$210{ }^{\circ} \mathrm{C}$. It was previously established by thermogravimetry that in this temperature range, thermal elimination of $\mathrm{HCl}$ occurs, which catalyzes the polycondensation process [8]:

$$
2 \operatorname{Lign}-\mathrm{Cl}+\mathrm{R}(\mathrm{COOH})_{2} \longrightarrow \text { Lign }-\mathrm{O}-\underset{\|}{\mathrm{C}}-\mathrm{R}-\underset{\mathrm{O}}{\mathrm{C}}-\mathrm{O}-\operatorname{Lign}+2 \mathrm{HCl}
$$

The modified lignin was added in small portions with stirring to the acid melt. A granular, abrasion-resistant and hydrolytically stable product was obtained.

The polycondensation reaction can also occur with the participation of the carboxyl and hydroxyl groups of the modified lignins. However, the predominant participation of the chlorine atom in the reaction proves the fact that the use of modified lignins that do not contain chlorine in the synthesis of ion exchangers does not lead to the formation of a threedimensional structure, which was also noted by the authors of [8]. 
Thus, the following ion exchangers were obtained: CatClN - chlorine-nitro-lignin cation exchanger, $\mathrm{CatFCl}$ - fluorine-chlorine-lignin cation exchanger, $\mathrm{CatClF}$ - chlorinefluorine-lignin cation exchanger, CatNClF - nitrated chlorine-fluorine-lignin cation exchanger, amphoteric chlorine-nitro lignin ion exchanger IonClN.

The authors of the publication [8] previously synthesized cation exchanger and ampholyte based on CINL, but ethylene glycol was used instead of phthalic acid. Ampholyte data served for comparative analysis in Table 5.

\section{Properties and characteristics of ion exchange materials}

The acidity constants for acidic $-\mathrm{COOH}$ and phenolic $-\mathrm{OH}$ groups participating in ion exchange were determined by potentiometric titration. According to the data in Table 2, the exchange of ions involves mainly carboxyl groups in the range of $\mathrm{pK} \alpha$ 1.9-6.8 and phenolic hydroxyl groups at $\mathrm{pK} \alpha$ 9.5-10.5.

Table 2. Acidity constants of ion exchangers.

\begin{tabular}{|c|c|c|c|c|c|}
\hline \multirow{2}{*}{ Functional groups } & \multicolumn{5}{|c|}{ Cation exchangers } \\
\cline { 2 - 6 } & CatCIN & CatFCI & CatCIF & CatNCIF & IonCIN \\
\hline $\begin{array}{c}- \text { COOH with an acceptor substituent } \\
\text { in the } \alpha \text {-position }\end{array}$ & 2.05 & - & - & 1.9 & 1.8 \\
\hline- COOH phthalic acid & 2.65 & 3.1 & - & - & - \\
\hline- COOH aliphatic & 6.8 & 6.5 & 5.5 & 6.00 & 6.7 \\
\hline$-\mathrm{OH}$ phenolic & 9.5 & 10.1 & 10.20 & - & 10.1 \\
\hline
\end{tabular}

In ion exchangers CatClN, CatNClF, IonCIN containing $\mathrm{NO}_{2}$ group, $\mathrm{COOH}$ groups with an acceptor substituent in the $\alpha$-position participate in the ion exchange, due to which the exchange capacity values increase (table 3 ).

Sorption value of metal cations by the salt form of cation exchangers significantly exceeds the sorption by the H-form (Table 3). This is explained by the fact that the kinetics of the exchange of the "sodium - metal" ion pair is higher than the "hydrogen - metal" due to the better dissociation of the salt form of weakly acidic groups and the smaller difference in the radii of the hydrated ions. The predominant sorption of iron ions is explained by the presence of quinone groups in the cation exchangers, which can be oxidized or reduced in the presence of cations of variable valence [8]. It should be noted that the authors of some publications draw attention to the good sorption of $\mathrm{Cr}$ (VI) ions by cation exchangers based on lignin [16, 17]. Cation exchanger CatNClF was distinguished by good exchange characteristics among the studied cations (Table 3), however, its low chemical stability did not allow its use after 2-3 regeneration cycles.

The best chemical resistance and mechanical strength were observed for cation exchangers CatClN and CatClF. The physicochemical characteristics of these cation exchangers in comparison with those already known are presented in Table 4. As follows from the data in the table, the exchange capacity under static conditions of the cation exchangers obtained by us is higher than that of $\mathrm{CatCl}$ [8] and $\mathrm{CU}-2-8$. In terms of chemical resistance, they are not inferior to $\mathrm{CatCl}$ and surpass $\mathrm{CU}-2-8$. 
Table 3. Cation exchange capacity under static conditions at cations sorption from $0.1 \mathrm{~mol} / 1$ solution.

\begin{tabular}{|l|c|c|c|c|c|c|c|c|}
\hline \multirow{2}{*}{ Cation } & \multicolumn{7}{|c|}{ Cation exchange capacity, mmol/g: } \\
\cline { 2 - 9 } & \multicolumn{2}{|c|}{ CatCIN } & \multicolumn{2}{c|}{ CatFCl } & \multicolumn{2}{c|}{ CatCIF } & \multicolumn{2}{c|}{ CatNCIF } \\
\cline { 2 - 9 } & $\begin{array}{c}\text { H- } \\
\text { form }\end{array}$ & $\begin{array}{c}\text { Na- } \\
\text { form }\end{array}$ & $\begin{array}{c}\text { H- } \\
\text { form }\end{array}$ & $\begin{array}{c}\text { Na- } \\
\text { form }\end{array}$ & $\begin{array}{c}\text { H- } \\
\text { form }\end{array}$ & $\begin{array}{c}\text { Na- } \\
\text { form }\end{array}$ & $\begin{array}{c}\text { H- } \\
\text { form }\end{array}$ & $\begin{array}{c}\text { Na- } \\
\text { form }\end{array}$ \\
\hline $\mathrm{Na}+$ & 9.0 & - & 8.0 & - & 8.8 & - & 6.4 & \\
\hline $\mathrm{Ba} 2+$ & 9.6 & - & 9.1 & - & 10.1 & - & 8.2 & \\
\hline $\mathrm{Fe} 3+$ & 1.39 & 4.59 & 0.99 & 4.6 & - & - & 1.11 & 4.45 \\
\hline $\mathrm{Ag}+$ & 0.85 & 3.12 & 0.7 & 2.86 & 0.91 & 3.4 & 1.13 & 3.8 \\
\hline $\mathrm{Cu} 2+$ & - & - & - & - & - & - & 1.28 & 4.05 \\
\hline $\mathrm{Ca} 2+$ & 0.77 & 3.28 & 0.32 & 3.08 & 0.66 & 3.22 & 1.14 & 3.9 \\
\hline $\mathrm{Ni} 2+$ & 0.72 & 3.04 & 0.27 & 2.5 & 0.51 & 2.55 & 1.1 & 3.78 \\
\hline
\end{tabular}

Table 4. Characteristics of cation exchangers CatClN and CatClF.

\begin{tabular}{|c|c|c|c|c|}
\hline Parameter & CatCIN & CatClF & CatCl* & CU-2-8** \\
\hline Bulk density, $\mathrm{g} / \mathrm{cm}^{3}$ & 0.42 & 0.41 & 0.38 & 0.36 \\
\hline Specific volume, $\mathrm{cm}^{3} / \mathrm{g}$ & 2.4 & 2.4 & 2.6 & 2.8 \\
\hline Swelling factor & 1.2 & 1.2 & 1.2 & - \\
\hline Thermal stability according to DTA, ${ }^{\circ} \mathrm{C}$ & 280 & 275 & 280 & - \\
\hline Mechanical stability, \% & 99.5 & 98.5 & 99.7 & - \\
\hline Chemical resistance to $5 \mathrm{~mol} / \mathrm{l} \mathrm{NaOH}, \%$ & 94 & 92 & 93.0 & 85 \\
\hline Exchange capacity for $0.1 \mathrm{~mol} / \mathrm{l} \mathrm{NaOH}, \mathrm{mmol} / \mathrm{g}$ & $8.7-9.1$ & $8.4-9.0$ & $5.8-6.4$ & 5.0 \\
\hline $\begin{array}{l}\text { Exchange capacity for } 0.1 \mathrm{~mol} / 1 \mathrm{NaOH} \text {, } \\
\mathrm{mmol} / \mathrm{cm}^{3}\end{array}$ & 3.6-3.8 & $3.5-3.8$ & $2.2-2.5$ & 1.8 \\
\hline
\end{tabular}

The cation exchanger CatCIN can be reduced with sodium sulfide, while it turns into an ampholyte IonCIN, capable of sorbing both cations and anions. The $\mathrm{NO}_{2}$ groups and partially carbonyl groups undergo reduction: 


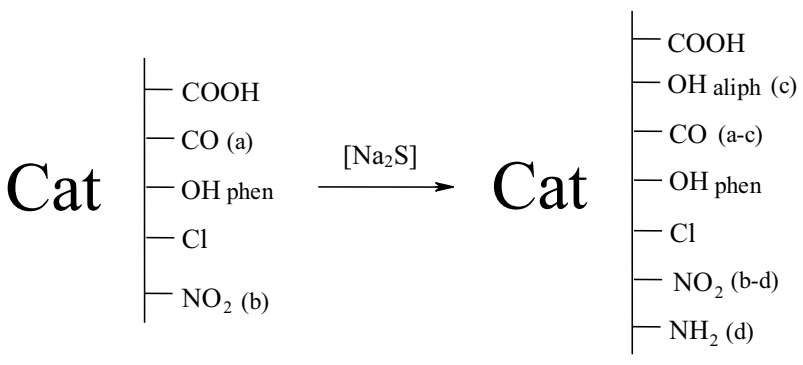

Cation exchangers CatClN and CatClF have close values of exchange and physicalmechanical properties and chemical resistance. However, the fluorine atom in the structure of the cation exchanger, most likely, does not affect the properties of the ion-exchange material. Table 5 shows the physicochemical properties of the IonCIN ampholyte.

Table 5. Characteristics of IonCIN in comparison with EDE-10P (GOST 20301-74) anion exchanger.

\begin{tabular}{|c|c|c|c|}
\hline Parameter & IonCIN & Ampholyte [8] & EDE-10P \\
\hline Particle size, $\mathrm{mm}$ & $0.25-1.50$ & $0.2-1.5$ & $0.4-2.0$ \\
\hline Bulk density, $\mathrm{g} / \mathrm{cm}^{3}$ & 0.75 & 0.7 & 0.3 \\
\hline Specific volume, $\mathrm{cm}^{3} / \mathrm{g}$ & 1.33 & 1.42 & 3.4 \\
\hline $\begin{array}{l}\text { Exchange capacity, mmol/g: } \\
\text { for } 0.1 \mathrm{~mol} / 1 \mathrm{NaOH} \text { - cation exchanger } \\
\text { for } 0.1 \mathrm{~mol} / 1 \mathrm{HCl} \text { - anion exchanger }\end{array}$ & $\begin{array}{l}8.5-8.8 \\
1.1-1.3\end{array}$ & $\begin{array}{l}8.0 \\
1.0\end{array}$ & $\begin{array}{c}- \\
7.7\end{array}$ \\
\hline $\begin{array}{l}\text { Exchange capacity, } \mathrm{mmol} / \mathrm{cm}^{3} \text { : } \\
\text { for } 0.1 \mathrm{~mol} / 1 \mathrm{NaOH} \text { - cation exchanger } \\
\text { for } 0.1 \mathrm{~mol} / 1 \mathrm{HCl} \text { - anion exchanger }\end{array}$ & $\begin{array}{l}6.4-6.6 \\
1.5-1.7\end{array}$ & $\begin{array}{l}5.6 \\
1.4\end{array}$ & $\begin{array}{c}- \\
2.3\end{array}$ \\
\hline $\begin{array}{c}\text { Chemical resistance, } \% \\
\text { to acids } \\
\text { to alkalis }\end{array}$ & $\begin{array}{l}90.0 \\
75.0\end{array}$ & $\begin{array}{l}93.4 \\
88.0\end{array}$ & $\begin{array}{l}70.0 \\
60.0\end{array}$ \\
\hline
\end{tabular}

Thus, the synthesized ampholyte IonCIN has high exchange characteristics for the chlorine anion and sodium cation. The static exchange capacity of IonCIN as an anion exchanger is approximately 1.5 times lower than that of an industrial anion exchanger. The chemical resistance to acids and alkalis of the IonCIN ampholyte is higher than that of the EDE-10P anion exchanger.

\section{Conclusion}

On the basis of polyfunctional lignins, weakly acidic cation exchangers with a static exchange capacity of $3.5-3.8 \mathrm{mmol} / \mathrm{cm}^{3}$ (specific volume $2.4 \mathrm{~cm}^{3} / \mathrm{g}$ ) were obtained. Ion exchangers are capable of sorbing cations in a wide range of $\mathrm{pH}$ values and have high exchange and physic-mechanical characteristics. 
It was found that the modification of lignins with fluorine does not increase the ionexchange characteristics of cation exchangers based on polyfunctional lignins. Therefore, further synthesis of the fluorine-containing cation exchanger $\mathrm{CatClF}$ and the recommendation for its use are considered inappropriate.

During the reduction of the cation exchanger CatCIN, ampholyte IonCIN was obtained, the static exchange capacity of which for the cation is $6.4-6.6 \mathrm{mmol} / \mathrm{cm}^{3}$, for the anion $1.1-1.3 \mathrm{mmol} / \mathrm{cm}^{3}$ (specific volume $1.33 \mathrm{~cm}^{3} / \mathrm{g}$ ).

Among the studied ion exchangers synthesized on the basis of polyfunctional lignins, the best ion exchange properties are exhibited by the cation exchanger CatClN and ampholyte IonCIN.

\section{References}

1. G. Parvathy, A.S. Sethulekshmi, J.S. Jayan, A. Raman, A. Saritha, Process Safety and Environmental Protection, 145, 395-410 (2021), doi:10.1016/j.psep.2020.11.017.

2. J. Chen, A.E. Kazzaz, N.A. Mazandarani, et al., Molecules, 23(4), 868 (2018), doi.org/10.3390/molecules23040868.

3. M. Demir, Z. Kahveci, B. Aksoy, et a.1, Industrial and engineering chemistry research, 54(43), 10731-10739 (2015), doi: 10.1021/acs.iecr.5b02614

4. O. Popova, M. Serbinovskii, Russian Journal of Applied Chemistry 87(6), 818-823 (2014), doi: 10.1134/S1070427214060251.

5. O. Popova, M. Serbinovskiy, A. Abramova, European Journal of Wood and Wood Products, 73(3), 369-375 (2015), doi: 10.1007/s00107-015-0881-5

6. E. Evstigneev, Russian Journal of Applied Chemistry, 86(2), 258-265 (2013), doi.org/10.1134/S1070427213020201

7. O. Popova, T. Mal'tseva, E. Mar'yeva, K. Tarasenko, Russian Journal of General Chemistry, 88(8), 1331-1336 (2018). doi.org/10.1134/S1070363218060440

8. E. Kovalenko, L. Tikhonova, O. Popova, A. Aleksandrov, Russian Journal of Electrochemistry, 32(1), 72-76 (1996)

9. H. Li, Z. Yuan, X. Shang, et al, International Journal of Biological Macromolecules, 172, 10-18 (2021), doi.org/10.1016/j.ijbiomac.2020.12.206

10. F. Wu, L. Chen, P. Hu, et al., Bioresource Technology, 322, 124539 (2021), doi.org/10.1016/j.biortech.2020.124539.

11. H. Qian, J. Wang, L. Yan, Journal of Bioresources and Bioproducts, 5(3), 204-210 (2020), doi:10.1016/j.jobab.2020.07.006

12. Y. Zhang, S. Ni, X. Wang, et al., Chemical Engineering Journal, 372, 82-91 (2019), doi.org/10.1016/j.cej.2019.04.111

13. Y. Li, F. Wang, Y. Miao, et al., Bioresource Technology, 307, 123165 (2020), doi:10.1016/j.biortech.2020.123165

14. X. Chen, S. Sun, X. Wang, et al., Bioresource Technology, 295, 122297 (2020), doi.org/10.1016/j.biortech.2019.122297.

15. G. Zakis, Functional analysis of lignins and their derivatives (Riga: Zinatne, 1987)

16. N. Chen, G. Qiu, C. Huang, et al., Chinese Journal of Chemical Engineering, 27(10), 
2544-2550 (2019), doi.org/10.1016/j.cjche.2019.02.021

17. X. Shi, Y. Qiao, X. An, et al., Journal of Biological Macromolecules, 159, 839-849 (2020), doi:10.1016/j.ijbiomac.2020.05.130 